The Quarterly Journal of Austrian Economics

Volume 24 | No.3 | 431-449 | Fall 2021

WWW.QJAE.ORG

\title{
Keynesian Supply Shocks and Hayekian Secondary Deflations
}

\author{
LuCAS M. ENGELHARDT*
}

JEL Classification: E32, B53

Авstract: In response to the COVID-19 lockdown policies, Guerrieri et al. (2020) developed a new concept: the Keynesian supply shock. A Keynesian supply shock is an aggregate supply shock that leads to an even larger aggregate demand shock. This paper suggests that Keynesian supply shocks are very similar to the secondary deflations suggested by Hayek (1931), and US data from the 2007-09 financial crisis show that these concepts may help to explain employment dynamics in the midst of a crisis. This fact implies that long-standing policy advice based on Austrian business cycle theory would be useful in responding to Keynesian supply shocks.

$\mathrm{T}$

The economic impacts of COVID-19 and the policies surrounding it have provided the grounds for extensive work in economics, especially surrounding public policy responses to the pandemic. Much of this work (for example, Eichenbaum, Rebelo, and Trabandt 2020) is based on integrating epidemiology models into standard models of macroeconomic activity. However, one exception to this trend is the introduction of a seemingly new, and possibly more generalizable, idea: "Keynesian supply shocks" (Guerrieri, et al. 2020). Keynesian supply shocks are shocks to aggregate supply that, in turn, lead to a shock to aggregate demand that is even larger than

\footnotetext{
* Lucas M. Engelhardt (lengelha@kent.edu) is an associate professor at Kent State University's Stark campus and a fellow of the Mises Institute. 
the original supply shock, so that the demand shock dominates the macroeconomic dynamics. Put another way, a Keynesian supply shock is a supply shock with a traditional demand-side multiplier. This new concept calls into question the separability of aggregate supply and aggregate demand.

This paper suggests that there is a significant conceptual overlap between Keynesian supply shocks and Hayek's concept of a "secondary deflation," in which an initial crisis focused on the liquidation of malinvestments leads to economy-wide consequences (Hayek 1931). If the two concepts are related, then the work on Keynesian supply shocks provides an additional approach that Austrian business cycle theorists can draw from for empirical illustrations, and Austrian business cycle theory has implications for policy prescriptions when dealing with the resulting recessions. Because Keynesian supply shocks are a new concept, there is very little literature directly connected with them yet. This paper serves as an early attempt to bring this concept into contact with the much older Hayekian "secondary deflation."

In addition to explaining the theoretical overlap between Keynesian supply shocks and Hayekian secondary depressions, this paper will show that employment data from the United States during the 2007-09 financial crisis is more consistent with the Keynesian supply shock/Hayekian secondary deflation theory than is employment data from the 2020 COVID-19 lockdowns, which inspired Guerrieri et al. (2020) to develop the Keynesian supply shock concept. This observation suggests that these two concepts have an applicability that is not bound by the rather odd case of the COVID-19 crisis.

\section{“KEYNESIAN" SUPPLY SHOCKS}

What is a "Keynesian supply shock"? In short, a Keynesian supply shock is a supply shock that causes a decrease in aggregate demand that is larger than the original supply shock (Guerrieri, et al. 2020). If we think in terms of standard aggregate supply-aggregate demand analysis, a Keynesian supply shock would create a leftward shift in both aggregate supply and aggregate demand, with the aggregate demand shift dominating. The result is a more severe recession than either shock alone would have caused, but also a decrease in the price level. As a result, if analysts casually observe price levels 
and real gross domestic product (GDP) levels, they will conclude that an aggregate demand shock was the primary force driving macroeconomic dynamics, when in fact the underlying cause of the demand shock is the shock to aggregate supply.

The motivation for the idea of a Keynesian supply shock was the shutdown of nonessential businesses in many places in the world during the coronavirus pandemic, especially during the early phases (for example, Michigan's Executive Order 2020-42, which closed all in-person work which was "not necessary to sustain or protect life"). Guerrieri et al. (2020) find that, under specific conditions, the partial shutdown of supply can lead to a demand shock that is more severe than the direct impact of the supply shock itself.

Guerrieri et al. (2020) model the shutdown as a temporary decrease in labor supply, and judge whether the aggregate supply or aggregate demand shock dominates by considering the effect on the natural rate of interest. ${ }^{1}$ In their model, the discount rate is kept constant so that the natural rate of interest will vary because of changes in the marginal utility of consumption. If the marginal utility of consumption for the present period rises relative to the expected future marginal utility of consumption, then the natural interest rate rises (consistent with the argument of Böhm-Bawerk [1930]), which is interpreted as being consistent with the dominance of the aggregate supply shock, because the relatively high marginal utility of present consumption indicates that there is a significant unsatisfied demand for present consumption goods. On the other hand, if the marginal utility of consumption for the present period falls relative to the future marginal utility of consumption, then the natural interest rate falls, which is interpreted as being consistent with the dominance of the aggregate demand shock.

First, they consider a case in which there is a single sector which is partially shut down by lockdown orders. ${ }^{2}$ Here, one can consider a

\footnotetext{
${ }^{1}$ They also evaluate how labor demand would compare to labor supply if wages and prices were fixed and the rate of interest were not allowed to move to its natural level, though this layer of analysis does not change the broader analysis.

${ }^{2}$ They consider both "complete" markets - where there is an insurance program or lending market that evenly distributes any changes in employment opportunities and "incomplete" markets, in which some workers face borrowing constraints. However, the qualitative results are the same for these two cases.
} 
number of ways that the results could work out. First, the decrease in available consumption goods would tend to increase the natural rate of interest, as consumers expect an increase in consumption in future periods when the shutdown ends, leading to a relatively higher marginal utility of (relatively more scarce) current consumption when compared to the marginal utility of (relatively more abundant) future consumption. Looking at the phenomenon from another angle, the shock to labor supply would lead to an increase in equilibrium wages. In terms of total income, the increase in wages would at least partially offset the decrease in employment, so that there is not much of a decrease in aggregate demand-leading supply effects to dominate. The only exception is if laid-off workers decrease their consumption in proportion with their lost income, in which case the supply shock is matched by an equal demand shock such that the natural rate of interest is unchanged. However, this is unlikely in reality because laid-off workers tend to borrow or spend from their savings in anticipation of an improvement in labor markets when the shutdown ends, in addition to partaking of any unemployment insurance or other government relief measures that are likely to be made available (such as that provided by the 2020 Coronavirus Aid, Relief, and Economic Security [CARES] Act in the United States. ${ }^{3}$ In brief: if the entire economy is a single sector which is partially shut down by lockdowns, supply shocks are not "Keynesian" - they do not lead to significant shocks in aggregate demand. Notably, modeling the economy based on a "representative firm" - which effectively treats the economy as a single sector-is a common practice in mainstream macroeconomics.

However, in a two-sector economy, the story changes. In this version of the model, employees completely specialize in one of two sectors, and the shutdown affects just one sector (the "nonessential"), leaving the other ("essential") sector to operate as usual. So, consumers are forced to go without the products of the nonessential sector but can continue consuming from the essential sector as normal. In this case, what happens to demand depends on two parameters: the parameter that governs consumers' willingness to substitute consumption

\footnotetext{
${ }^{3}$ One could also observe that consuming nothing when income drops to zero would soon result in death $-\mathrm{a}$ fairly powerful incentive to maintain nonzero consumption even if earned income has fallen to zero.
} 
across time, and the parameter that governs the relationship between the goods produced by the two sectors. First, the more willing people are to substitute consumption across time, the larger the negative impact on the essential sector will be-as those workers that are laid off when the nonessential sector shuts down simply wait to consume until later periods. Second, if the goods from the essential sector and the nonessential sector are complements in consumption, then a negative impact on aggregate demand arising from the supply shock is more likely. Since the good from the nonessential business is no longer available, people have less demand for the complementary good from the essential business. In short, the loss of the nonessential good decreases the current marginal utility of the essential good, which can drive down the natural interest rate. If, on the other hand, people are not willing to substitute consumption across time and the two goods are substitutes, then consumers will tend to significantly increase their demand for the essential good to maintain current overall consumption during the lockdown, so that the supply shock does not create a "Keynesian" ripple effect on aggregate demand. Put another way, when the goods are substitutes, the loss of one good increases the marginal utility of the other-leading to a higher natural interest rate, reflecting the dominance of the aggregate supply shock.

The above applies in the model which assumes "complete markets" (that is, markets where workers have unemployment insurance or largely unconstrained credit, so that any fall in current consumption is divided equally among workers). Once the fact that markets are "incomplete" - that is, that lost income is mostly going to be experienced by those that are laid off because of the shutdown policies-is accounted for, the conditions that lead to decreased aggregate demand are widened. That is, some scenarios that would lead to "standard" supply shocks if markets were complete end up with significant Keynesian demand ripples because of the severe loss of income (and therefore decrease in consumption) for those employed in the nonessential sector, who have no choice but to decrease their consumption because of the diminished availability of unemployment insurance or lending markets in this model.

In another version of the model, the possibility of labor mobility between sectors is introduced. In this case, the demand shock is more likely to dominate than when labor mobility is limited. As workers flood the sector that is still open, the good produced by the 
essential sector experiences a temporary boom, which tends to push down the current marginal utility of consumption, and therefore tends to push down the natural interest rate. Put another way: the ability of workers to move between sectors offsets the severity of the supply shock, allowing the demand effects to dominate.

Guerrieri et al. also consider a case of a "demand chain" in which nonessential businesses purchase services from essential businesses. For example, restaurants (which have been severely hampered by lockdown policies [Honan and Vielkind 2020]) sometimes purchase the services of accounting firms (which may be considered "essential" simply because they can operate with minimal physical contact). In this case, the loss of nonessential clients during the shutdown can end up having additional demand-side effects for essential businesses, making large "Keynesian" ripples more likely. Notably, they do not consider a case in which essential businesses purchase services from nonessential businesses-though in that case the supply shock would be magnified through the supply channel, as those businesses that rely on inputs from the shut-down nonessential businesses would find their own supply constrained. For example, if farmers (which are considered essential) purchase work gloves from garden supply stores (which were deemed nonessential in some areas), then the productivity of farmers would decline, so that the supply shock would ripple through the structure of production but would maintain a supply shock nature. Amid the COVID-19 crisis, some jurisdictions recognized the difficulties this could cause, and so considered suppliers of any essential business to also be essential. For example, Ohio's stay-at-home order included "Businesses that sell, manufacture, or supply other Essential Businesses and Operations with support or materials necessary to operate" on the list of essential businesses.

Finally, they consider a model with a multitude (technically, a continuum) of sectors in which there may be "exit cascades." In this model, the shutdown of one sector leads to a decline in demand which can result in another sector being unable to cover its fixed costs of operation, leading at least some firms in that sector to shut down as well, leading to a further decline in demand for the remaining firms and further exits. These ripples can create significant demand-side effects. 
Summarizing the findings of Guerrieri et al. (2020), if there are multiple sectors in the economy, the supply shock caused by the shutdown of one sector can create demand-side effects that are more significant than the original shutdown. These demand-side effects are magnified to the extent that (1) employees of the shut-down industry have incomplete protection against losses of wages, (2) the goods produced by the shut-down sector are complementary to the goods produced by other sectors, (3) consumers are more willing to shift consumption across time, (4) labor can reallocate itself across sectors, (5) the shut-down sectors are an important source of demand for the sectors continuing to operate, and (6) exit cascades occur. Since multiple sectors do exist, and at least some of these magnifying factors are plausible, it is reasonable to believe that supply shocks may end up turning "Keynesian" in many cases.

\section{AUSTRIAN BUSINESS CYCLES AND SECONDARY DEFLATION AND DEPRESSION}

At heart, Austrian business cycle theory is about a misallocation of resources between sectors (that is, "malinvestment"). During a period of credit expansion, entrepreneurs invest in production processes that are expected to be profitable, though they will ultimately end up being unprofitable. When the period of credit expansion ends, the errors of the entrepreneurs are revealed, resulting in a recognition that production must be restructured to eliminate the misallocation of capital.

An important element of the Austrian approach is that Austrians generally expect that misallocation will be most severe in specific sectors of the economy-that is, a multiple sector approach is an essential component of the Austrian explanation for business cycles. "Capital intensive" sectors that are early in the stages of production will be heavily affected, as these sectors are more sensitive to distortions in interest rates than others. Typically, this set of sectors would include fields such as research and development or raw material production, which are likely to result in consumer goods only after a long period of time. Housing is another example of the type of good that may be vulnerable during Austrian business cycles. Although housing may appear to be a consumer good, it provides housing services over a very long period-decades or 
sometimes centuries—so that a new home is at an early stage in the production of housing services.

How can one translate the Austrian-style crisis and collapse into aggregate supply and aggregate demand terms? Generally, Austrians are fast to point out that aggregation will tend to cover up the important dynamics (for example, Hayek 1935), and therefore obscure what is happening within the capital structure. This is consistent with the findings of Guerrieri et al. (2020). In their models, when sectors are aggregated into a single sector, the possibility of a Keynesian supply shock vanishes-so aggregation covers up the important dynamics in their model, even if the dynamics are more connected to employment than to capital structure. Despite the differences in the theoretical foundations of aggregate supply-aggregate demand analysis and the Austrian approach, one can think of the aggregate supply-aggregate demand approach as simply trying to divide the sources of economic fluctuations into two broad categories: disruptions to production and disruptions to spending, especially on final goods.

Keeping this division in mind, during the credit expansion, the capital structure will tend to lengthen, as there is additional investment in the very early stages of production. However, at the same time, there is a drive toward overconsumption (Salerno 2012), as low interest rates make real saving unattractive. In the words of Garrison $(2001,72)$,

\footnotetext{
At some point in the process ... entrepreneurs encounter resource scarcities that are more constraining than was implied by the pattern of wages, prices, and interest rates that characterized the early phase of the boom.... The bidding for increasingly scarce resources and the accompanying increased demands for credit put upward pressure on the interest rate.
}

In brief, the crisis in Austrian business cycle theory has traits that resemble a supply shock. First, resource scarcity leads to a disruption in production. Second, as in the Guerrieri et al. (2020) models, where supply shocks dominate, an increase in interest rates accompanies the crisis.

One additional trait of the Austrian business cycle is the potential for secondary effects that feel very much like a Keynes-style "demand shock." In his review of John Maynard Keynes's 1930 A 
Treatise on Money, Friedrich Hayek suggested the possibility of a "secondary deflation" in response to the reallocation process that happens amid the Austrian crisis:

[T] he very fact that processes of investment have been begun but have become unprofitable as a result of the rise in the price of the factors and must, therefore, be discontinued, is, of itself, a sufficient cause to produce a decrease of general activity and employment (in short, a depression).... The decrease in consumption comes only as a result of unemployment in the heavy industries.... I do not deny that, during this process, a tendency towards deflation will regularly arise; this will be particularly the case when the crisis leads to frequent failures. (Hayek $1931,42,44)$

Put in slightly different terms, the collapse of those sectors where malinvestments were concentrated leads to an unemployment wave, which creates a decrease in the demand for consumer goods, and frequent failures (which seem to resemble exit cascades) promote a more severe decline by creating deflationary pressures in credit markets. From Hayek's description, the deflationary pressures are likely caused by the failures of fractional reserve banks, which lead to a collapse in the money supply. Building on Hayek, Garrison $(2001,75)$ describes it so: "[S]elf-reversing changes in the capital structure give way to a self-aggravating downward spiral in both income and spending." He then explains that an increase in liquidity preference-driven by the recognition of the high levels of risk in the midst of an economic crisis-would be a likely result of the situation. There is a subtle difference between Hayek and Garrison. In Garrison's analysis, bank failures are not required for this secondary spiral to occur. Instead, an increase in the demand for money, which may keep prices from rising or lead them to fall, suffices. Salerno (2012) provides additional reasons for the perception of higher risks in the crisis, pointing out that during the bust, entrepreneurs see that the economic calculation that they believed served them well in the past has failed. This failure leads to a loss of confidence in their own forecasts and in economic calculation itself. In the words of Salerno $(2012,37)$, these psychological phenomena "are a rational response to the calculational chaos." Fleshing out some of the conditions that lead to these downward spirals, Huerta de Soto $(2012,453)$ notes that secondary depressions are most likely when "wages are inflexible, hiring conditions very 
rigid, union power great, and governments succumb to the temptation of protectionism."

The overlap between Keynesian supply shocks and the Austrian secondary deflation or secondary depression is multifaceted. First, both phenomena involve a fundamentally supply-side restriction that began in one sector and leads to demand-side effects in other sectors, specifically through changes in spending behavior, and especially in consumption spending. Second, neither of these phenomena is a logical necessity - it is at least possible that the conditions may not be right for them to occur. Although the set of conditions that lead to a secondary depression posited by Hayek (1931), Garrison (2001), Salerno (2012), and Huerta de Soto (2012) do not exactly align with the parametric conditions described by Guerrieri et al. (2020), there is significant conceptual overlap. For example, in Guerrieri et al. (2020), rigid wages and interest rates mean that the demand shock would appear in the form of unemployment.

However, Keynesian supply shocks and Austrian secondary depressions do have somewhat different causes. The underlying malinvestment and resulting intertemporal discoordination in the capital structure is a specific phenomenon suggested by Austrian business cycle theory. Meanwhile, Guerrieri et al. (2020) are largely agnostic about what causes the initial supply shock, their motivating story being an entirely policy-driven initial shock. (Since their model omits capital, they certainly would not be able to capture the process described by Austrian business cycle theory.) The Austrian explanation, then, is more comprehensive, but Guerrieri et al. (2020) can provide a possible explanation for the link between the initial crisis and the broader effects in the secondary depression. Another difference between the two approaches is the view of time. The Austrian theory sees the events as playing out across time, while Guerrieri et al. (2020) compress time so that the initial supply shock and resulting demand shock all happen in the same period. This comes from the mathematical structure they use, which sees the economy as moving from one equilibrium state to another, with less attention paid to the transition between equilibria. Disaggregating not just across sectors but across time will be an important element in identifying the existence of ripple effects between sectors in the historical illustrations that follow. 


\section{APPLICATION TO 2006-09 FINANCIAL CRISIS}

As an illustration of how a shock in one sector can create broader effects, as would be the case in a Keynesian supply shock or an Austrian secondary depression, consider the timing of employment effects during the 2007-09 financial crisis. This crisis was caused by excessively low interest rates, which led to too many resources being directed toward investment in housing construction. As interest rates rose, housing values collapsed and the financial sector experienced related difficulties. Eventually, these difficulties spread to the economy on a broader scale. To see this effect, consider the level of employment in construction and in financial activities compared to all other sectors in the United States.

Figure 1. Employment in construction and finance, January 2005 to October 2010

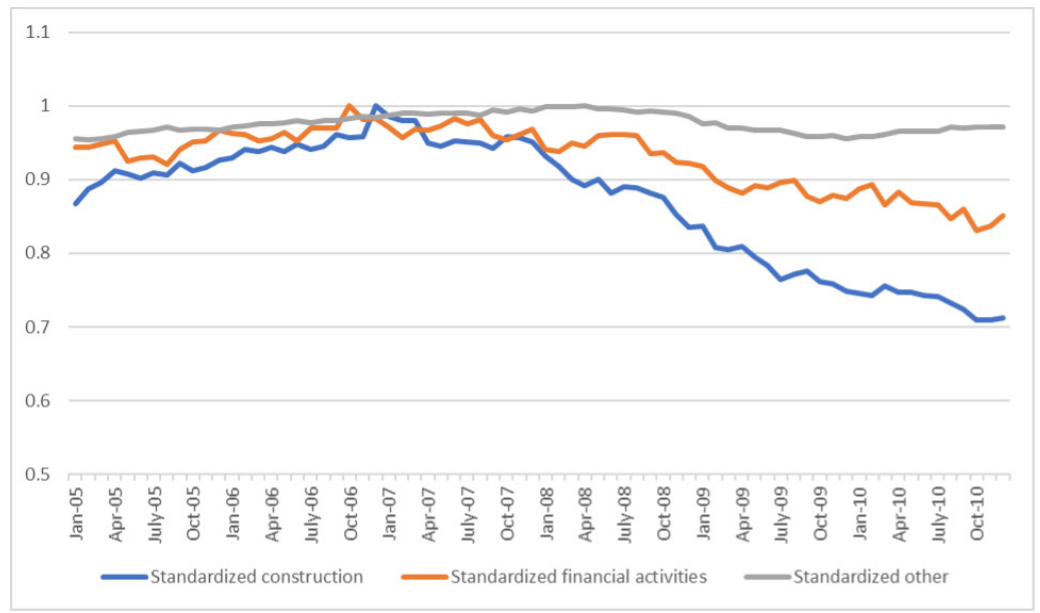

Source: Data from the US Bureau of Labor Statistics Current Employment Survey.

In figure 1, each series is normalized so that the employment level at the peak for that series in this time frame takes a value of 1 . The data reveals that the peak employment for financial activities was in October 2006. Construction followed soon after, in December 2006. The other sectors as a group, however, did not peak until April 2008-about eighteen months after the peak in financial 
activities employment. (The National Bureau of Economic Research [NBER] recognizes December 2007 as the official beginning of this recession-at which point employment in the initiating sectors had already fallen by about 5 percent, though employment in other sectors was stable or slightly rising.) As additional evidence of the primary importance of Financial Activities and Construction, one may note that by December 2010, four full years after the employment peak, financial activities shed about 15 percent of the jobs it had at its peak, while construction shed nearly 30 percent, and these series were still declining. The Producer Price Index (PPI) for building material and supplies dealers is also consistent with the Keynesian supply shock theory over this period. From January 2006 to the peak PPI in September 2006, there was an increase of over 10 percent in this PPI-consistent with the idea that builders were bidding against one another for limited resources, as Hayek describes, and as would be expected in a sector-specific supply shock. These prices fell back as the construction sector neared its employment peak. So, it seems that production was limited on the supply side in construction and that this led, a few months later, to a decline in employment in that sector-which later created secondary demand-side effects, as seen in employment data for indirectly affected sectors.

\section{APPLICATION TO THE 2020 COVID-19 CRISIS}

Guerrieri et al. (2020) present their theory in connection with the COVID-19-related shutdowns. Interestingly, the data does a significantly poorer job of showing a "Keynesian supply shock" in this period than during the financial crisis that happened a decade earlier. 


\section{Figure 2. Employment in various sectors during the COVID-19 shutdowns, January-June 2020}

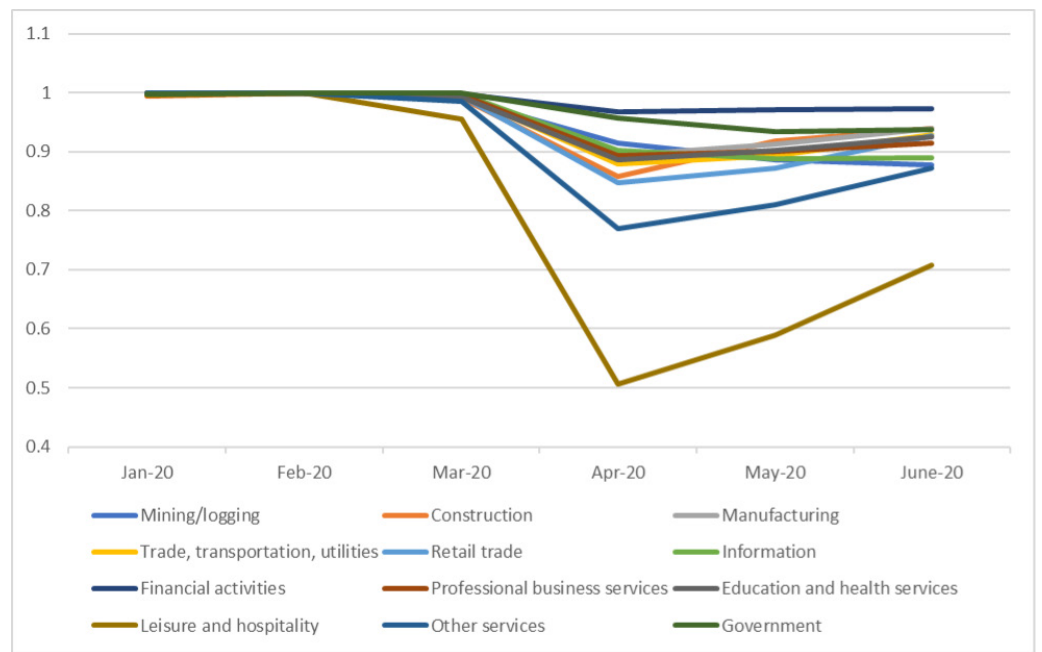

Source: Data from the US Bureau of Labor Statistics Current Employment Survey.

Figure 2 shows the normalized employment from the Current Employment Survey from the US Bureau of Labor Statistics, divided by supersector. In this case, every supersector peaked in February 2020, with just one exception: trade, transportation, and utilitieswhich had a January employment figure 0.0007 percent higher than in February. (Meanwhile, for retail trade specifically, the peak is in February, as you find in other sectors.) Also, nearly every sector had its lowest post-peak level of employment in April, after a small decline in March. The exceptions were employment in mining/ logging, information, and government, which continued to decline into at least May (mining/logging descended through August [not shown]). Every other sector bounced back. This certainly does not match what one would expect from the Keynesian supply shock theory: immediate impacts in the sectors most directly affected by the shutdowns (leisure and hospitality, which includes restaurants and hotels, for example, is a clear candidate for "first round" effects) and then secondary effects in those sectors less directly impacted (accounting - a part of professional business services sector-is specifically mentioned in Guerrieri et al. [2020] as a field that would 
experience these effects). Although the most severe employment effects were seen in the more directly affected sectors (leisure and hospitality as well as "other services"), there does not appear to be even a one-month lag between the employment collapse in the most impacted sectors and other industries. Those that experienced the longest delays (such as mining/logging), moreover, seem, intuitively, to be unlikely victims of a demand-side ripple effect, as it seems implausible that layoffs in leisure and hospitality led them to decrease their demand for ores and lumber. Because the data shows no clear demand-side ripples, the COVID-19 shutdowns are more consistent with a traditional supply shock.

Before dismissing the Keynesian supply shock concept as unimportant in the COVID-19 shutdowns, three observations are worth making. First, as previously noted, Guerrieri et al. (2020) compress time. Naturally, this is not realistic if a single day is considered a period. However, since employment data has a monthly frequency, the question is whether the fundamental supply-side shock could have demand-side employment effects within a month, so that the available data would appear to be affected simultaneously. The answer here is not obvious, but the possibility cannot be entirely ruled out. Second, the full effects of this crisis are not yet known. In the previous financial crisis, there was an eighteen-month delay between the peak in the initiating sectors and peak in other sectors. It may be that enough time to observe the secondary depression simply has not passed. However, the data at this point does not seem consistent with the Keynesian supply shock theory. Third, policymakers have been attacking the COVID-19 crisis with aggressive stimulus measures, both fiscal and monetary. This stimulus may have managed to cover up much of the secondary depression. In short, while the data does not show a clear Keynesian supply shock, this shock could be occurring but simply not have appeared in the available data.

\section{POLICY IMPLICATIONS}

Throughout their paper, Guerrieri et al. (2020) suggest the importance of expansionary monetary policy to ameliorate the employment problems created by lockdown policies. Exactly how expansionary monetary policy would have to be depends on the 
specific version of their model. In many cases, all that is required to achieve the first-best outcome-that is, as mild a recession as possible, given that the direct effect of the lockdowns cannot be avoided-is to allow real interest rates to fall to the natural rate (defined on the basis of time preference and the marginal utility of consumption across time periods). However, there are some cases when a strongly expansionary monetary policy that pushes the real interest rate below the natural rate is recommended-for example, when the loss of an employer-employee "match" would create a loss in productivity after the shutdown ends. In addition, Guerrieri et al. (2020) emphasize the importance of social insurance-redistributing lost income from those who do not experience job losses to those who do experience job losses-as ameliorating some of the broader losses in well-being from shutdowns by moving markets closer to being "complete."

The policy front is where the similarity between Keynesian supply shocks and Austrian secondary depressions has its greatest practical value. Based on the original framework that inspired the idea of the Keynesian supply shock-a framework in which capital goods are entirely absent and social insurance is assumed not to create moral hazards-expansionary monetary policy and social insurance appear to be clearly beneficial. However, considering Austrian insights, the misguided nature of these policy prescriptions-particularly advocating expansionary monetary policy-becomes clear. In the words of Hayek (1931, 44), "Any attempt to combat the crisis by credit expansion will, therefore, not only be merely the treatment of symptoms as causes, but may also prolong the depression by delaying the inevitable real adjustment." This would especially be the case in the more typical business cycles that experience "Keynesian supply shock" effects (such as the financial crisis). Plus, as argued by Suntum (forthcoming), money that is created through credit markets tends to push interest rates below the natural rate, which would ensure the Hayekian effects described above.

If we confine the idea of Keynesian supply shocks to the COVID-19 lockdowns, then the expansionary monetary policy and social insurance programs suggested by Guerrieri et al. (2020) are less objectionable. In this case, the bust was induced by the shutdown of those sectors deemed nonessential rather than by a 
recognition of a misallocation of resources. As a result, expansionary monetary policy will not prolong a necessary reallocation, and its ability to create a new Austrian-style boom is limited by continuing lockdown policies. However, if expansionary policy continues after the lockdowns are lifted, then the normal Austrian analysis regarding credit expansion would become relevant. With social insurance programs, a significant concern is that such programs disincentivize work. However, given COVID-19-related public health concerns, reducing contact between employees and coworkers may have benefits that normally would not exist. Although this does not imply that the benefits of these policies outweigh the costs, it is worth recognizing that there are potential benefits that would not apply in normal circumstances. In short, the policies that Guerrieri et al. (2020) suggest for offsetting the secondary demand shock have more benefits and fewer costs than normal in the presence of COVID-19-related health concerns and lockdowns. However, the employment data examined does not clearly point to any significant secondary demand-side effects so far. In the absence of secondary demand-side effects, policies to offset them are clearly unnecessary. In short, the COVID-19 crisis seems to be primarily a traditional supply shock, but policy induced. If this is the case, as long as the damage done is not irreversible, the economy will recover when supply is freed of its policy-induced constraints-and this has already been observed in the very fast bounce back in both employment and GDP as restrictions in most states were partially loosened shortly after the initial lockdown.

However, there is good evidence of "Keynesian supply shock" effects during the previous financial crisis. Disruptions in the financial and construction sectors were clearly followed by ripples (albeit limited) in the rest of the economy. But in this kind of situation, it is socially beneficial to allow employer-employee matches in the bloated sectors to be broken, so that workers can allocate their skills elsewhere. Interventions aimed at keeping these matches in place-such as a paycheck protection program or expansionary monetary policy—will have the effect that Hayek emphasized: simply delaying the necessary adjustments. Similarly, resource use will improve if, along with labor, capital is reallocated out of bloated sectors and into sectors that were not stimulated by the previous credit expansion. And, certainly, during a typical 
economic downturn, there are no significant public health concerns that might lead to changes in the optimal approach by making minimizing unnecessary contact a desirable goal.

In the end, the policy prescriptions suggested by Guerrieri et al. (2020) are least objectionable in the COVID-19 crisis-where the evidence that the underlying theory applies is relatively weak. On the other hand, in the 2007-09 financial crisis, there is much stronger evidence that the underlying theory applies, but the policy prescriptions suggested were implemented (at least in part), and likely created negative consequences by prolonging the misallocations that led to the crisis in the first place.

\section{CONCLUSIONS AND AREAS FOR FURTHER RESEARCH}

This paper takes the new concept of Keynesian supply shocks presented by Guerrieri et al. (2020)—inspired by the containment policies used to combat COVID-19-and connects it with the old concept of secondary deflation presented by Hayek (1931). The connection between these two concepts provides a bridge between Austrian business cycle theory and more mainstream approaches to macroeconomic fluctuations, and the data surrounding the 2007-09 financial crisis, which has proven to be a great demonstration of Austrian business cycle theory, is consistent with elements of the Keynesian supply shock/secondary deflation progression (much more so than the data from the 2020 COVID-19 crisis). The similarity between these phenomena allows for Austrian business cycle theorists to provide insights into the policy prescriptions that are suggested by those advocating the idea of Keynesian supply shocks-ideas such as expansionary monetary policy to preserve job matches, which is particularly undesirable given the necessity of reallocating malinvested capital.

One question that this paper raises is how well this perspective could help explain other business cycles across time. Both the Keynesian supply shock and Austrian secondary deflation approaches suggest that the standard Keynesian interpretation of a demand-driven business cycle may simply be describing a secondary effect, while the primary effect is fundamentally a supply-side disruption. The Keynesian supply shock framework 
also confirms the benefit of disaggregating data-and specifically employment data-by sector or industry to help uncover the true story of any crisis.

The data presented here also raises questions about how to interpret the economic fluctuations of 2020. Do they have a particularly "Austrian" nature? For example, how can an Austrian approach to capital structure help aid understanding of the impacts of the shutdown? Are policies that would create problems in a typical business cycle-such as those designed to preserve employer-employee matches-potentially beneficial in the presence of other policies creating their own set of problems-such as the forced temporary shutdowns of "nonessential" businesses? Are the COVID-19 shutdowns a case where the middle-of-the-road policy would lead toward socialism, or is there a logical stopping point, so that this slope is not as slippery as it might seem? Although the current economic situation does not seem to justify such policies, in an age where interventionism is the dominant view among policymakers, it would be best to have answers ready when their time comes.

\section{REFERENCES}

Böhm-Bawerk, Eugen. 1930. The Positive Theory of Capital. New York: G. E. Stechert.

Eichenbaum, Martin S., Sergio Rebelo, and Mathias Trabandt. 2020. “The Macroeconomics of Epidemics." NBER Working Paper Series 26882, March. https://www.nber.org/papers/w26882.

Garrison, Roger W. 2001. Time and Money: The Macroeconomics of Capital Structure. New York: Routledge.

Guerrieri, Veronica, Guido Lorenzoni, Ludwig Straub, and Iván Werning. 2020. "Macroeconomic Implications of COVID-19: Can Negative Supply Shocks Cause Demand Shortages?" NBER Working Paper Series 26918, April. https://www.nber.org/papers/w26918.

Hayek, Friedrich A. 1935. Prices and Production. 2d ed. London: Routledge. . 1931. "Reflections on the Pure Theory of Money of Mr. J. M. Keynes (Continued)." Economica, no. 35, 22-44. 
Honan, Katie, and Jimmy Vielkind. 2020. "Gov. Andrew Cuomo Orders New York City Restaurants to Stop Indoor Dining." Wall Street Journal, Dec. 11, 2020.

Huerta de Soto, Jesús. 2012. Money, Bank Credit, and Economic Cycles. Translated by Melinda A. Stroup. 3d ed. Auburn, Ala.: Ludwig von Mises Institute.

Salerno, Joseph T. 2012. "A Reformulation of Austrian Business Cycle Theory in Light of the FInancial Crisis." Quarterly Journal of Austrian Economics 15, no. 1: 3-44.

Suntum, Ulrich van. Forthcoming. "Natural Interest Rate and Money Interest Rates." Economists' Voice. Published ahead of print, Nov. 12, 2020. https://doi.org/10.1515/ev-2019-0028. 